Proc. Estonian Acad. Sci. Biol. Ecol., 2004, 53, 3, 161-178

\title{
Influence of fast ship waves on the optical properties of sea water in Tallinn Bay, Baltic Sea
}

\author{
Ants Erm* and Tarmo Soomere \\ Marine Systems Institute, Tallinn University of Technology, Akadeemia tee 21, 12618 Tallinn; \\ ants@phys.sea.ee and tarmo@phys.sea.ee \\ Received 13 January 2004, in revised form 28 February 2004

\begin{abstract}
Wake waves from fast ferries create significant changes in the optical parameters of sea water in the near-bottom layer with a thickness of about $1 \mathrm{~m}$ in coastal areas of Tallinn Bay with depths of about $2-5 \mathrm{~m}$. The suspended matter remains in the water column for about $5 \mathrm{~min}$. Rough quantitative estimates, based on the wave-induced increase of the suspended matter in the water column per unit of bottom of the coastal area (about $1 \mathrm{~g} \mathrm{~m}^{-2}$ ) suggest that the bulk influence of fast ferry traffic in Tallinn Bay may result in an annual loss of the order of $100 \mathrm{~L}$ of fine sediments from each metre of the coastal line.
\end{abstract}

Key words: optical measurements, underwater irradiance, high-speed ships, ship wakes, suspended matter.

\section{INTRODUCTION}

The waves from fast ferries have become a problem of growing concern in the vicinity of ship lanes in many countries during the last years (Kofoed-Hansen \& Mikkelsen, 1997; Kirk McClure Morton, 1998; Parnell \& Kofoed-Hansen, 2001; Varyani \& Krishnankutty, 2002). Their wave systems contain a massive amount of energy that may adversely affect the marine ecosystem (Guidelines, 2003). Since all waves, whether generated by wind or a by a vessel, always have some impact on the marine environment, it is generally believed that the effect of ship wakes is negligible in coastal areas that are open seawards and where natural waves are frequently much higher than the wakes (Lindholm et al., 2001). This assumption is indeed true for coasts exposed to high tidal waves or to dominating winds. However, in non-tidal seas, such as the Baltic Sea, hydrodynamic activity is governed by wind waves and currents. Owing to specific features of its geometry

* Corresponding author 
and the local wind regime, there may exist well-sheltered parts of its coastlines that are likely to be adversely impacted by ship wakes (Guidelines, 2003).

Tallinn Bay is a semi-open sea region (ca $10 \times 20 \mathrm{~km}$ ) in the central part of the Gulf of Finland, Baltic Sea. It has hosted an extremely heavy fast ferry traffic since 2000. During the high season, high-speed ships cross the gulf nearly 70 times daily. Their operation is frequently accompanied by violent breaking waves in certain coastal areas, suggesting a high overall anthropogenic wave load.

A recent study performed in 2001-2002 demonstrated that the heights of ship waves in the coastal areas of Tallinn Bay normally do not exceed $1 \mathrm{~m}$ (Soomere \& Rannat, 2003) and are moderate compared with the highest wind waves reaching this area each year (Soomere, 2003). The role of ship waves is the most impressive in terms of wave power since ship waves form 18-35\% of the annual mean total wave power at the coasts of Tallinn Bay. The anthropogenic waves may even dominate during a relatively calm part (April-June) of the high navigation season (Soomere et al., 2003).

The major threats to the coasts and the ecosystem of the bay arise from specific properties of the fast ferries' waves. The highest ship waves frequently have a height of about $1 \mathrm{~m}$ and the period of about $10 \mathrm{~s}$ (Soomere \& Rannat, 2003). Such waves do not exist in the area studied in natural conditions, therefore the ship traffic adds a qualitatively new key forcing factor to the local marine ecosystem (Soomere et al., 2003). In terms of near-bottom velocities, the impact of a typical ship wake on bottom sediments and aquatic wildlife at depths of 5-30 $\mathrm{m}$ is comparable with or even exceeds the impact of wind waves occurring in the most violent storms (Soomere \& Kask, 2003).

The primary reaction of seabed to an increased hydrodynamic activity consists in the intensification of resuspension processes provided the near-bottom orbital velocity exceeds a certain threshold. The intensity and extent of accompanying sediment transport processes are crucial factors in the assessments of the environmental impact of fast ferries (Guidelines, 2003; Soomere \& Kask, 2003). This reaction can be identified and roughly estimated with the use of optical measurements (Bauer et al., 2002), which are much more flexible and much less expensive than geological studies of the underwater sediment transport processes. The "optical" approach is particularly promising because it enables to directly quantify the influence of the increased wave activity on primary production (which is limited by the amount of light in the deeper part of the nearshore; Paalme, 1997). Since most of the fast ferry traffic is concentrated to the biologically active season and occurs during daytime, an overall worsening of underwater light conditions owing to the fast ferry operation is likely.

Optical methods have been successfully used for the classification of Estonian and Finnish lakes and for estimating their condition starting from 1992 (Arst et al., 1999, 2000; Erm et al., 1999, 2001, 2002; Reinart et al., 2001, 2003; Arst, 2003). In recent years the application of optical methods has been extended to coastal sea areas. Equipment similar to the one used in the current study allowed researchers to survey the under-ice light conditions and to estimate the concentrations of optically 
active substances in ice cover (Leppäranta et al., 2003; Erm \& Reinart, 2003). As to practical applications, optical methods are currently widely used for estimates of the environmental impact of dredging and underwater mining (Kask, 2003).

The current paper describes wave-induced changes of optical properties of sea water and the underwater light regime in the coastal area of Tallinn Bay. The experimental set-up, basic optical parameters, and changes of the optical properties of sea water in different parts of the water column are described. The amount of material resuspended by a single ship wake and the bulk sediment transport owing to fast ferry traffic is given following a per-ship-passage approach (Bauer et al., 2002). Further prospects of optical measurements of wave-induced effects are discussed.

\section{FIELD MEASUREMENTS AND METHODS}

A series of field experiments was performed in June and July 2003. The measurement sites (Fig. 1) were chosen near the jetty of Aegna. They are located in the vicinity of the sites where ship wakes and wind waves were traced and wake-induced changes of water properties were first detected in 2001-2002 (see above and Soomere et al., 2002; Soomere \& Rannat, 2003). The measurements were performed somewhat closer to the jetty than in 2001-2002 in order to allow video tracking of wakes. An extended analysis of the video recordings will be presented elsewhere. The ships passing the measurement sites are listed in Table 1. Frequently it was not possible to distinguish the wake of similar ships from each

Fig. 1. Study area. The dashed line shows the Tallinn-Helsinki ship lane.

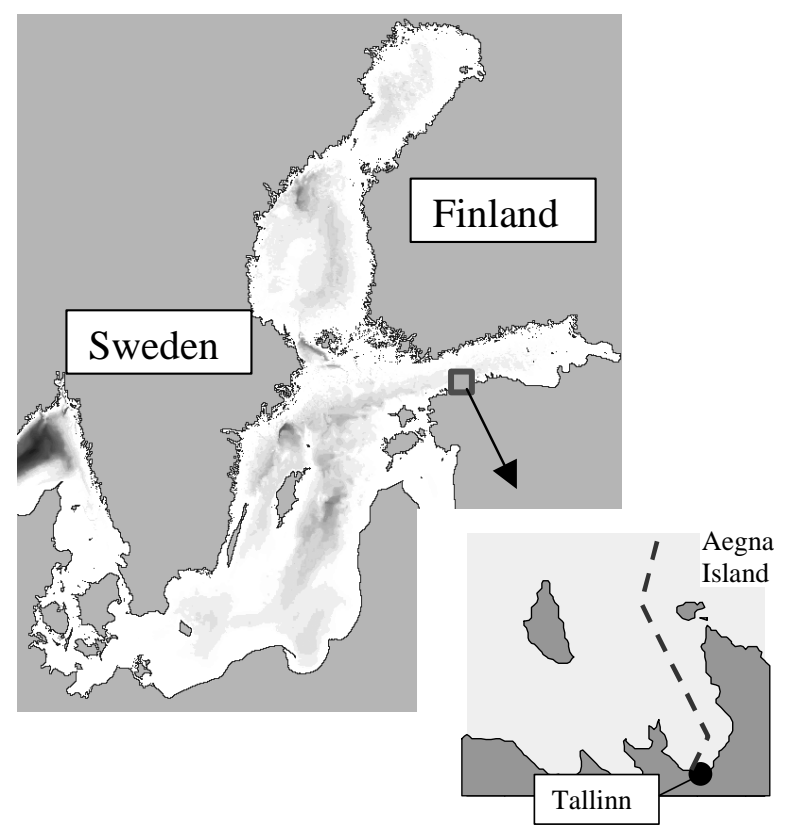


Table 1. Large high-speed ships passing the measurement sites at 07:00-15:30 on 17 and 20 July (after http://www.webmarine.ee/). Main technical data of the ships and properties of their wakes are described in (Soomere \& Rannat, 2003). Ships sailing to Helsinki (shown in bold) generally produce larger waves than those sailing to Tallinn. The leading waves arrive the measurement site about 4-8 min after the ship has passed

\begin{tabular}{l|c|c|c}
\hline \multicolumn{1}{c|}{ Ship } & $\begin{array}{c}\text { Departure from } \\
\text { Tallinn }\end{array}$ & $\begin{array}{c}\text { Approximate passing } \\
\text { time }\end{array}$ & Arrival in Tallinn \\
\hline SuperSeaCat & $07: 30$ & $07: 45$ & - \\
Nordic/Baltic Jet & $08: 00$ & $08: 15$ & - \\
AutoExpress/2 & $08: 00$ & $08: 15$ & - \\
AutoExpress/2 & - & $09: 00$ & $09: 15$ \\
SuperSeaCat & - & $09: 25$ & $09: 40$ \\
Nordic/Baltic Jet & - & $09: 25$ & $09: 40$ \\
AutoExpress/2 & $09: 50$ & $10: 05$ & - \\
SuperSeaCat & $10: 15$ & $10: 30$ & - \\
Nordic/Baltic Jet & $10: 15$ & $10: 30$ & - \\
AutoExpress/2 & - & $11: 25$ & $11: 40$ \\
Nordic/Baltic Jet & - & $11: 30$ & $11: 45$ \\
SuperSeaCat & - & $12: 20$ & $12: 35$ \\
Nordic/Baltic Jet & $12: 55$ & $13: 05$ & - \\
AutoExpress/2 & $13: 00$ & $13: 15$ & - \\
AutoExpress/2 & - & $13: 25$ & $13: 40$ \\
SuperSeaCat & $13: 30$ & $13: 45$ & - \\
Nordic/Baltic Jet & - & $13: 50$ & $14: 05$ \\
SuperSeaCat & - & $13: 55$ & $14: 10$ \\
AutoExpress/2 & $14: 30$ & $14: 45$ & - \\
SuperSeaCat & $14: 50$ & $15: 05$ & - \\
Nordic/Baltic Jet & $15: 00$ & $15: 15$ & - \\
& & &
\end{tabular}

other. For that reason, below we use the double names Nordic/Baltic Jet and AutoExpress/2 for the twin ships Nordic Jet and Baltic Jet, and for the AutoExpress and AutoExpress 2. We consider only large fast ferries, because wakes from other ships sailing in the Tallinn Bay area are practically undistinguishable from the natural wave background at the measurement sites (Soomere \& Rannat, 2003).

The experiments consisted of measurements of properties of ship waves with two wave recorders (SBE26 by Sea-Bird Electronics and a domestic device by PTR Group, both based on pressure sensors), simultaneous video tracking of the water surface, and measurements of optical properties of sea water. Additionally, water samples were taken from the near-bottom layers. Laboratory analysis of the samples was performed to quantify the amount of sediments re-suspended by ship-generated waves. The wave recorders were mounted on a rigid pillar equipped with a scale and firmly anchored on the sea bottom in a vertical position.

A frame with three optical sensors was anchored to sea bottom (Fig. 2) in the vicinity of the pillar. Three plane sensors Li192SA (for measuring downwelling 
Fig. 2. The mounting scheme of the optical sensors.

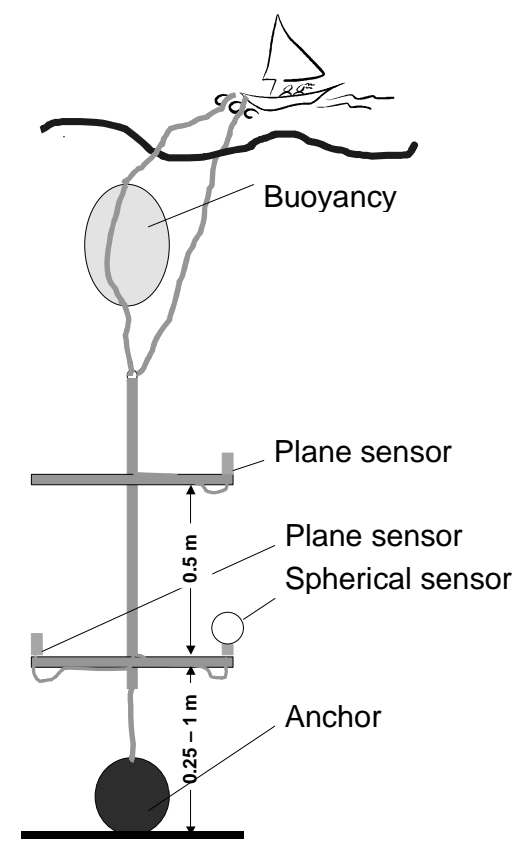

plane irradiance), one spherical sensor Li193SA (for measuring scalar irradiance), and a datalogger Li1400 produced by Li-Cor Corporation were used. These sensors measure the irradiance in the photosynthetically active region of light (400-700 nm, below denoted as PAR). They were rigidly mounted on the frame. The spherical sensor and the lower plane sensor were located at a distance of $0.5-0.7 \mathrm{~m}$ from the bottom. The upper plane sensor was mounted $0.5 \mathrm{~m}$ higher than the lower sensors (Fig. 2). The third plane sensor for incident irradiance and the datalogger were placed in a boat.

The theoretical basis of the light measurements is thoroughly discussed by Jerlov (1968) and Dera (1992) and was recently expanded to multicomponental waters such as lake water and brackish water in coastal areas by Arst (2003). The notations from (Arst, 2003) are used below. The downwelling vector irradiance

$$
E_{\mathrm{d}}(z)=\int_{0}^{2 \pi} d \alpha \int_{0}^{\pi / 2}|\cos \vartheta| L_{\mathrm{d}}(z, \vartheta, \alpha) \sin \vartheta d \vartheta
$$

was registered with the plane sensors. Here $\alpha$ and $\vartheta$ are the azimuth and zenith angles, respectively, $L_{\mathrm{d}}$ is the downwelling radiance, $z$ is the depth of the sensor, and the $z$-axis is directed upwards. The scalar irradiance

$$
E_{0}(z)=\int_{0}^{2 \pi} d \alpha \int_{0}^{\pi} L(z, \vartheta, \alpha) \sin \vartheta d \vartheta
$$

was measured with the spherical sensor. It is commonly used in marine biology (Jerlov, 1968) and characterizes the total amount of light available at a depth $z$. 
The diffuse attenuation coefficient (Dera, 1992)

$$
K_{\mathrm{d}}(z)=\frac{d}{d z} \ln E_{\mathrm{d}}(z)=\frac{1}{E_{\mathrm{d}}(z)} \frac{d E_{\mathrm{d}}(z)}{d z}
$$

characterizes the attenuation rate of the downwelling irradiance at a certain depth $z$. The larger this coefficient, the less light penetrates to the deeper layers. It was calculated from the field measurement data. Factually, $E_{\mathrm{d}}(z)$ was measured by two sensors at depths $z_{\mathrm{u}}$ (upper sensor) and $z_{1}$ (lower sensor). The distance between the sensors was $0.5 \mathrm{~m}$. An approximate average value of $K_{\mathrm{d}}$ in the water layer between the sensors can be estimated as

$$
K_{\mathrm{d}}\left(\frac{z_{1}+z_{\mathrm{u}}}{2}\right)=\frac{1}{z_{1}-z_{\mathrm{u}}} \ln \frac{E_{\mathrm{d}}\left(z_{1}\right)}{E_{\mathrm{d}}\left(z_{\mathrm{u}}\right)} .
$$

The directly measurable optical quantities $E_{\mathrm{d}}(z)$ and $E_{0}(z)$ mostly follow the downwelling irradiance. The influence of rapidly changing clouds frequently leads to relatively large temporal variation of the incident irradiance above the water surface $E(+0)$ and, as a result, also to a relatively large variation in the time series of $E_{\mathrm{d}}$. A typical situation of this kind is represented in Fig. 3 where

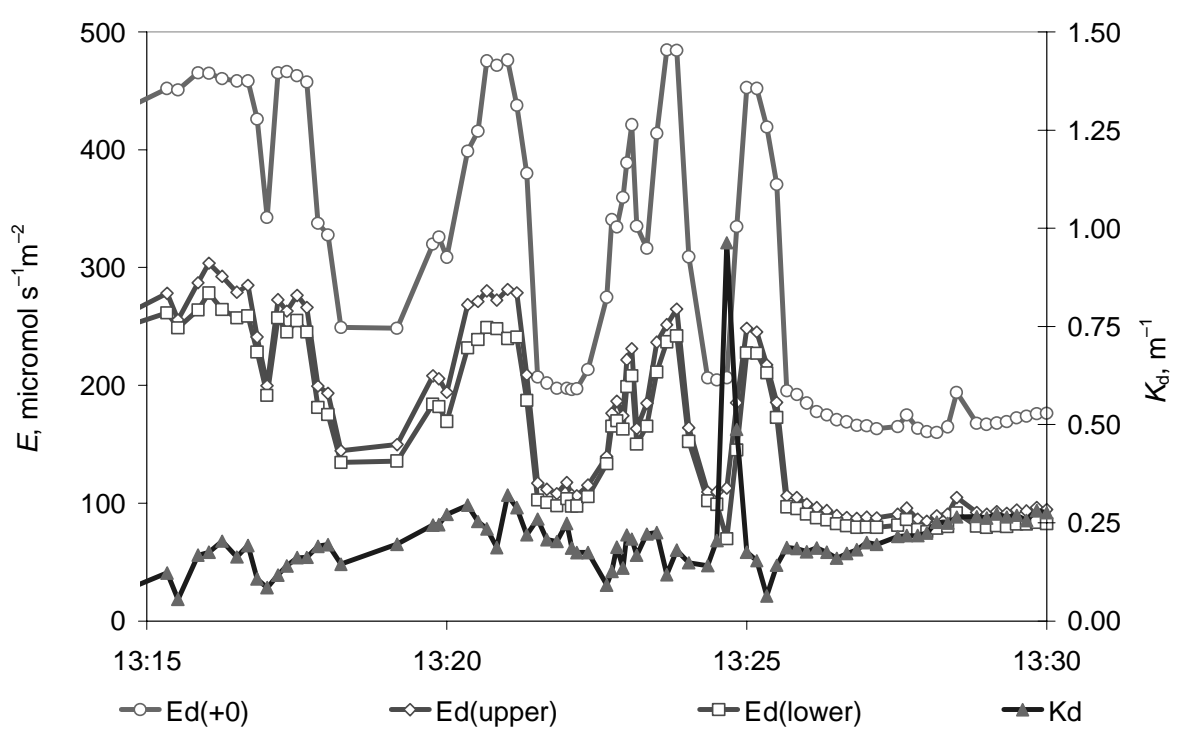

Fig. 3. Incident and underwater light field on 20 July 2003 in a sea area with a depth of $4.8 \mathrm{~m}$. $E_{\mathrm{d}}(+0)$ - the incident irradiance measured at the boat, $E_{\mathrm{d}}$ (upper) and $E_{\mathrm{d}}($ lower $)$ - the irradiances at depths of $1.2 \mathrm{~m}\left(E_{\mathrm{d}}\right.$ (upper) $)$ and $0.7 \mathrm{~m}\left(E_{\mathrm{d}}(\right.$ lower $\left.)\right)$ from the bottom, $K_{\mathrm{d}}-$ the diffuse attenuation coefficient of the water layer between the upper and lower sensors. The instantaneous values of the measured parameters are averaged over $5 \mathrm{~s}$. 
changes in $E_{\mathrm{d}}\left(z_{\mathrm{l}}\right)$ and $E_{\mathrm{d}}\left(z_{\mathrm{u}}\right)$ owing to ship waves are fully masked by the changes in $E(+0)$.

Besides the changing clouds conditions, the instantaneous values of $E_{\mathrm{d}}$ are greatly affected by the waves on the sea. First, they cause variation in the height of the water column above the firmly anchored underwater sensors. Secondly, they cause a practically stochastic variation of the scattering properties of the sea surface and in this way create high-frequency noise in the measured optical signal. However, the diffuse attenuation coefficient $K_{\mathrm{d}}(z)$ is independent of the described factors. Although it also contains some noise, it characterizes well optical properties of the sea water between the sensors. It frequently reacts drastically to ship waves. For example, Fig. 2 shows a clear maximum of $K_{\mathrm{d}}(z)$ at 13:24:20 corresponding to a wake of the AutoExpress sailing from Tallinn to Helsinki (departed at 13:00).

Water samples were taken with a batometer from the depth roughly corresponding to the water layer between the plane sensors. The samples were first analysed with a spectrophotometer Hitachi U1000. It measures the "spectrometric" attenuation coefficient $c^{*}(\lambda)$ (Arst, 2003)

$$
c^{*}(\lambda)=c(\lambda)-\Delta b(\lambda)-c_{\mathrm{d}}(\lambda)
$$

This quantity embraces the real beam attenuation coefficient $c(\lambda)$, the contribution of small-angle forward scattering to the measured radiation $\Delta b(\lambda)$ (which is $4-10 \%$ of the total scattering coefficient $b(\lambda)$ for a given wavelength $\lambda$; Zaneveld et al., 1992; Bricaud et al., 1995), and the light beam attenuation coefficient of distilled water $c_{\mathrm{d}}(\lambda)$. The actual values of $b(\lambda)$ in lakes with a Secchi disc depth of 2-6 m normally are $0.5-1 \mathrm{~m}^{-1}$ (Herlevi et al., 1999).

Further, the concentration of suspended matter $C_{\mathrm{s}}$ was determined by its dry weight after filtering the water through Millipore membrane filters HAWG047S1, made of mixed cellulose esters (nitrate and acetate), with a pore size of $0.45 \mu \mathrm{m}$. The effective concentration of yellow substance in the water samples $C_{\text {ye }}$, affecting both the diffuse and beam attenuation coefficients, was estimated from the filtered water using the following approximation:

$$
c_{\mathrm{f}}^{*}(\lambda) \approx a_{\mathrm{y}}(\lambda)=\tilde{a}_{\mathrm{y}}\left(\lambda_{0}\right) C_{\mathrm{ye}} \exp \left[-S\left(\lambda-\lambda_{0}\right)\right] .
$$

Here $a_{\mathrm{y}}(\lambda)$ is the absorption coefficient, $\tilde{a}_{\mathrm{y}}\left(\lambda_{0}\right)=0.565 \mathrm{~L} \mathrm{mg}^{-1} \mathrm{~m}^{-1}$ is the specific absorption coefficient of the yellow substance at the reference wavelength $\lambda_{0}=380 \mathrm{~nm}$, and $S=0.017 \mathrm{~nm}^{-1}$ is the slope parameter (Mäekivi \& Arst, 1996). The chlorophyll $a$ concentration $C_{\mathrm{chl}}$ was determined by filtering the water samples through Whatman GF/C glass microfibre filters (pore size $1.2 \mu \mathrm{m}$ ), extracting the pigments with hot ethanol $\left(90 \%, 75^{\circ} \mathrm{C}\right)$ and measuring the absorption at wavelengths of 665 and $750 \mathrm{~nm}$ (Lorenzen, 1967). 


\section{CHANGES OF OPTICAL PROPERTIES OF SEA WATER}

The SW coast of Aegna, located about $2 \mathrm{~km}$ from the Tallinn-Helsinki ship lane, was chosen for the combined hydrodynamical and optical measurements for two reasons. First, the properties of ship-generated waves (Soomere \& Rannat, 2003) and the features of the sea bottom occurring in this area (Kask et al., 2003) are well studied. Second, the neighbourhood of Aegna jetty allows convenient video tracking of the water surface at the measurement site.

In this study we discuss the results measured at two points located at depths 2.1 and $4.8 \mathrm{~m}$. Optical properties of sea water at these sites were typical for the Baltic Sea conditions. The Secchi depth was about $5 \mathrm{~m}, C_{\mathrm{s}}=2-5 \mathrm{~g} \mathrm{~m}^{-3}$, $C_{\mathrm{chl}}=1-2 \mathrm{mg} \mathrm{m}^{-3}$, and $c^{*}(\mathrm{PAR})=0.6-1 \mathrm{~m}^{-1}$ (cf. Fig. 6 below). The values of $C_{\text {ye }}=1.9-2.2 \mathrm{~g} \mathrm{~m}^{-3}$ were quite stable during the whole measurement series showing that the concentration of yellow substance in the sea water in the area studied was relatively homogeneous. The highest ship-generated waves were, as expected, about $50-80 \mathrm{~cm}$ at both sites.

During the experiments at the first site (water depth of $2.1 \mathrm{~m}$ ) on 17 July 2003 the weather conditions were particularly favourable for optical measurements. The cloudiness was $1 \mathrm{Ci}$, the wind speed was about $2 \mathrm{~m} \mathrm{~s}^{-1}$, and the significant height of the natural wave background was about $20 \mathrm{~cm}$. A typical record of the response of optical properties of sea water on ship wakes is shown in Fig. 4. An increasing trend in the values of $E(+0), E_{\mathrm{d}}\left(z_{1}\right)$ (lower plane sensor), and $E_{\mathrm{d}}\left(z_{\mathrm{u}}\right)$ (upper plane sensor) follows the change of the position of the Sun. A certain scatter in

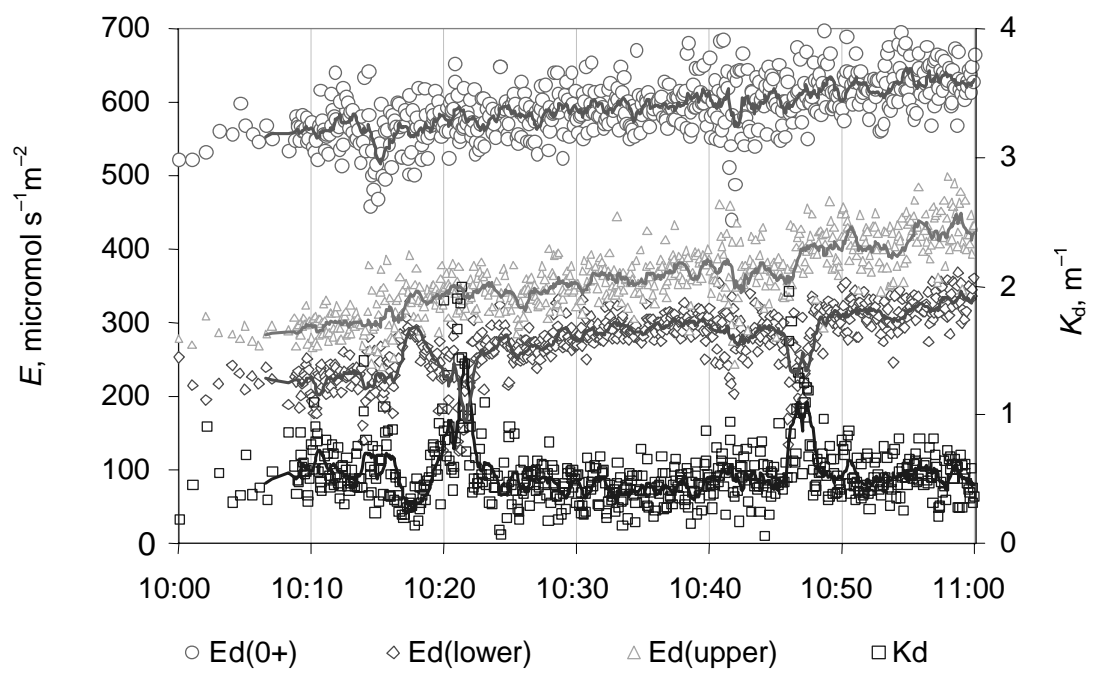

Fig. 4. Incident and underwater light field on 17 July 2003 in a sea area with a depth of $2.1 \mathrm{~m}$. $E_{\mathrm{d}}(+0)$ - the incident irradiance measured at the boat, $E_{\mathrm{d}}$ (upper) and $E_{\mathrm{d}}($ lower $)$ - the irradiances at depths of $1.0 \mathrm{~m}\left(E_{\mathrm{d}}\right.$ (upper) $)$ and $0.5 \mathrm{~m}\left(E_{\mathrm{d}}(\right.$ lower $\left.)\right)$ from the bottom, $K_{\mathrm{d}}-$ the diffuse attenuation coefficient of the water layer between the upper and lower sensors. The instantaneous values of the measured parameters (averaged over $5 \mathrm{~s}$ ) and a moving average over 10 subsequent measurements are shown. 
their values is apparently caused by irregular changes of the position of the sensor in the small boat or the boat itself. The wakes induced by the Autoexpress/2, SuperSeaCat, and Nordic/Baltic Jet (arriving at the measurement site at 10:18, 10:42, and 10:46, respectively) practically did not affect the optical signal of the upper plane sensor but caused certain changes exceeding the typical level of the noise in its time series in the signal recorded by the lower plane sensor. However, the maximum increase of $K_{\mathrm{d}}(t)$ was about fourfold (from 0.5 to $2.0 \mathrm{~m}^{-1}$ ).

On 20 July 2003, during the experiments at the other site in a deeper area $(4.8 \mathrm{~m})$, the cloudiness was $5 \mathrm{Cu}$, the wind speed was about $4 \mathrm{~m} \mathrm{~s}^{-1}$, and the background wave height was about $30 \mathrm{~cm}$. As mentioned above, due to the rapidly changing sky conditions, the directly measured values of $E_{\mathrm{d}}\left(z_{1}\right)$ and $E_{\mathrm{d}}\left(z_{\mathrm{u}}\right)$ varied greatly (Fig. 3) during part of the measurements. Yet a clear maximum of $K_{\mathrm{d}}$ at 13:24:20 corresponds to a wake of the AutoExpress/2 sailing from Tallinn to Helsinki.

However, there were time intervals when $E_{\mathrm{d}}\left(z_{1}\right)$ and $E_{\mathrm{d}}\left(z_{\mathrm{u}}\right)$ were more or less constant. The behaviour of optical parameters (Fig. 5a) and pressure (Fig. 5b) during the time interval 14:50-15:20 represents three wakes from high speed ships. A wake from the AutoExpress arrived at about 14:55 and wakes from the SuperSeaCat and the Nordic/Baltic Jet at 15:13 and 15:17. All these ships sailed to Helsinki. As expected, the leading waves of the ship wakes reached the measurement site about 5 min after the ship was at the traverse.

The wakes caused a substantial decrease (30-40\% of its typical value) of the downwelling irradiance in the near-bottom water layer (about $0.7 \mathrm{~m}$ from the sea bottom). The decrease is considerably larger than the natural variability of $E_{\mathrm{d}}\left(z_{1}\right)$, and occurs for a limited time interval with a duration of about $5 \mathrm{~min}$ (cf. Bauer et al., 2002). The reduction is also much larger than an analogous variability at the abovedescribed shallower measurement site. The diffuse attenuation coefficient $K_{\mathrm{d}}$ reacts to ship waves very strongly at this site. It increases about five times (from 0.2 to $1 \mathrm{~m}^{-1}$ ) during the time interval 13:15-13:30 (Fig. 3) and particularly dramatically

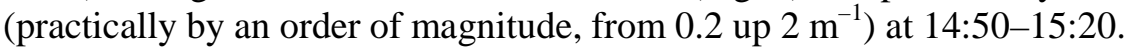

The described effects apparently were caused by ship-generated wave packets since the background wave field was practically constant. Indeed, they occurred synchronously with the passing of ship wakes through the measurement area (cf. Fig. 5a and b). Note that in Fig. 5a the pressure data are plotted because the signal of ship waves is usually better identifiable in the pressure time series than in the water surface time series (Soomere \& Rannat, 2003).

During the said time intervals, the downwelling irradiance $E_{\mathrm{d}}$ remained practically constant at about $1.2 \mathrm{~m}$ above the bottom. It is important to stress that there were no substantial changes in the optical signal of the upper plane sensor either at the shallower or at the deeper measurement site. This feature shows that, at least for the depths of the experiments, a single ship wake only affects the optical properties of water from the near-bottom layer with a thickness of about $1 \mathrm{~m}$.

The scalar irradiance $E_{0}(z)$, measured with a spherical sensor at the depth of the lower plane sensor, does not show any considerable reaction to the ship wakes (Figs. 4, 5) either. Therefore, an increase in the water turbidity owing to ship 


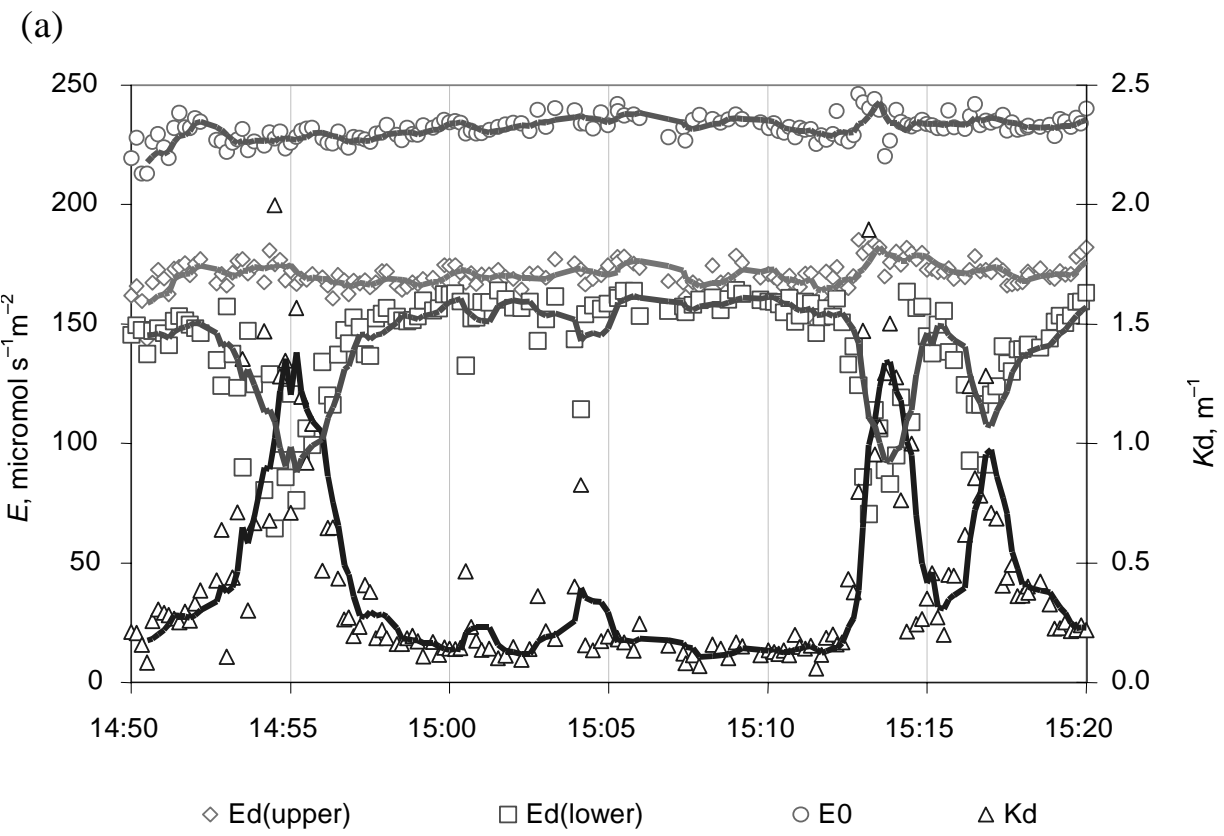

(b)

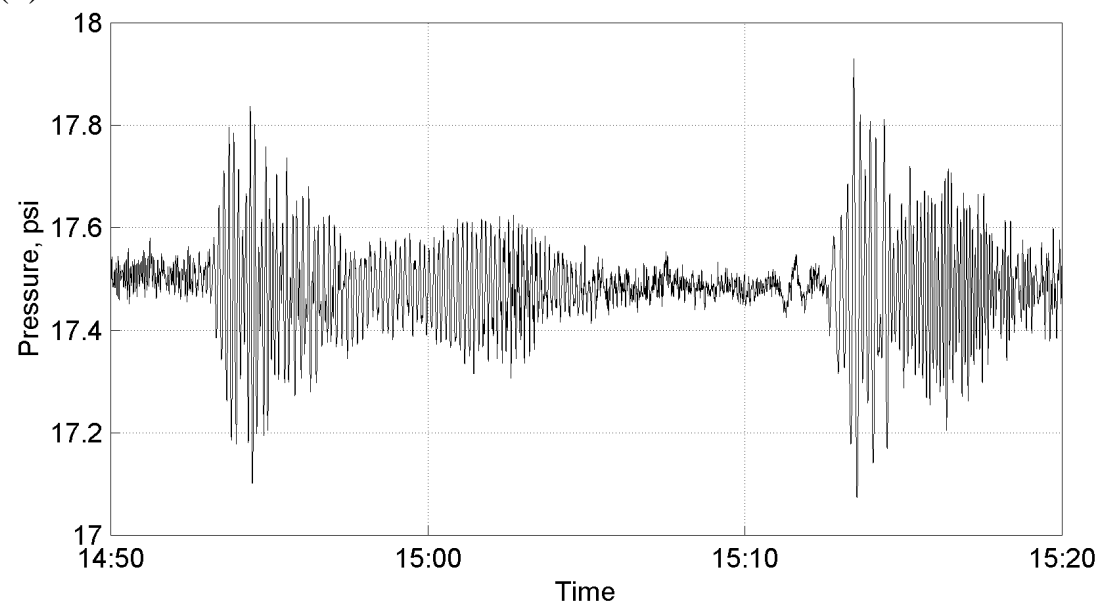

Fig. 5. (a) Underwater light field in the afternoon of 20 July 2003 in a sea area with a depth of $4.8 \mathrm{~m}$. The normalized (using the values of incident vector irradiance $E_{\mathrm{d}}(+0)$ ) plots of downwelling vector irradiance at depths of $1.2\left(E_{\mathrm{d}}\right.$ (upper) $)$ and $0.7 \mathrm{~m}\left(E_{\mathrm{d}}(\right.$ lower $\left.)\right)$ from the bottom, and scalar irradiance $\left(E_{0}\right)$ at a depth of $0.7 \mathrm{~m}$ from the bottom, and $K_{\mathrm{d}}$ - the diffuse attenuation coefficient of the water layer between the upper and lower sensors. The instantaneous values of the measured parameters (averaged over $5 \mathrm{~s}$ ) and a moving average over 5 subsequent measurements are shown. (b) Wake waves in the pressure signal. The highest single wave is about $1 \mathrm{~m}$. 
wakes does not necessarily mean an overall decrease in the amount of light at certain depths. The decrease of the downwelling irradiance can be simply compensated for by an increase in the scattered light owing to particles raised up by ship waves. Also, for the optically pure waters in the area studied and small depths of the measurement sites (which were smaller than the Secchi depth), a substantial part of the scalar irradiance may be irradiance reflected from the bottom.

The overall changes of the optical density of water were estimated through comparison of the results of spectral analysis of water samples. The samples were taken with a vertical batometer from the depth between the plane sensors early in the morning of the measurement days (well before the ship traffic started) and after several high-speed ships had passed but well after the last passage. The absolute values of $c^{*}(\lambda)$ before and after the passing of a single wake from the SuperSeaCat on 17 July were both small, mostly about $1 \mathrm{~m}^{-1}$. According to Arst (2003) so low values of $c^{*}(\lambda)$ are characteristic of optically pure waters and the observed small changes in their values lie within the range of measurement errors. However, the beam attenuation coefficients showed an increase in the whole photosynthetically active region (Fig. 6), suggesting that the optical density of water samples increased already with the beginning of ship traffic.

The beam attenuation coefficients increased more than twice owing to the bulk influence of wakes from nine fast ferries in the morning of 20 July between 07:30 and 10:50 AM. In the long-wave part of the spectrum the values of $c^{*}(\lambda)$ exceeded $1.5 \mathrm{~m}^{-1}$, suggesting that its variation reliably matches the changes

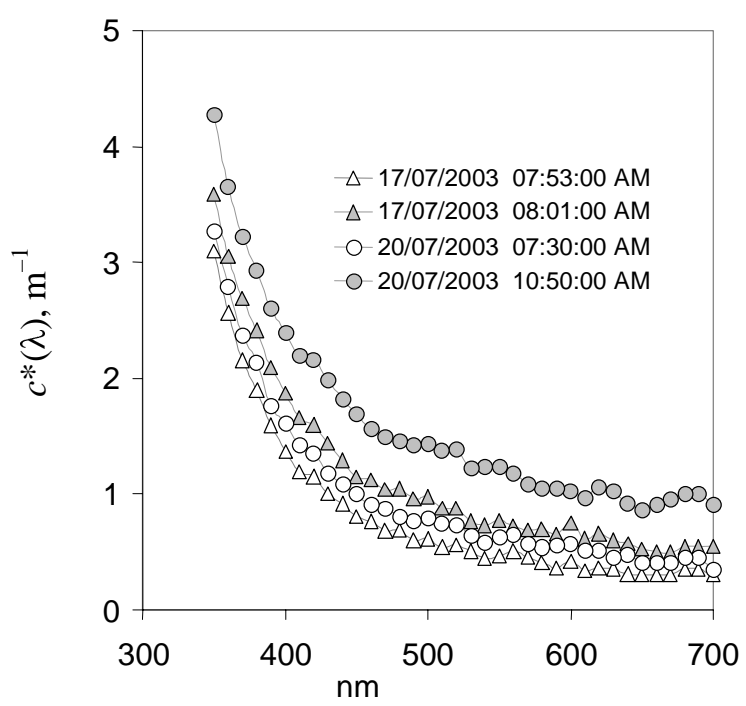

Fig. 6. Spectra of the beam attenuation coefficient $\left(c^{*}(\lambda)\right)$ for the near-bottom water on 17 and 20 July before (open symbols) and after (filled symbols) the fast ferry wakes reached the measurement area. 
of optical properties of sea water (cf. Arst, 2003). The changes of $c^{*}(\lambda)$ are generally larger than typical measurement errors, and also exceed the possible variation of optical properties of sea water owing to an increase in its chlorophyll content, suggesting that the bulk influence of ship traffic indeed results in an increase of optical density of water in coastal areas of Tallinn Bay.

\section{RESUSPENSION AND TRANSPORT OF SEDIMENTS}

A number of water samples were taken from the layer between the plane sensors immediately after the leading wake waves arrived. The arriving time of the ship wakes was not known in advance, because it greatly depended on the properties of a particular wake, which may considerably vary even for a single ship (Soomere \& Rannat, 2003). The samples were typically taken 1-3 min after the leading waves (that apparently caused the largest changes in the optical properties of sea water in Figs. 4, 5) had arrived. Therefore, these data characterize relatively long-term changes of properties of sea water rather than the optical properties of water in the most intense part of the wake.

The batometers are cylinders with a length of about $0.4 \mathrm{~m}$. Consequently, their length is comparable with the bottom layer with an increased content of suspended matter. Owing to this feature full replacement of water in batometers did not necessarily occur during the lowering of the instruments, and several water samples may contain a certain portion of pure water from upper layers. Thus, the estimates below should be considered as mostly qualitative, showing actually the lower limit of wave-induced changes of water properties.

Changes in parameters of water samples are shown in Fig. 7. The concentration of yellow substance $C_{\text {ye }}$ was practically constant during the whole experimental campaign. This suggests that the above-described changes of optical properties of water were indeed caused by changes of either the concentration of suspended matter $C_{\mathrm{s}}$ or chlorophyll $C_{\mathrm{chl}}$. Generally, the concentrations of both components were the lowest in the early morning and changed more or less synchronously. An abrupt increase in $C_{\text {chl }}$ in the morning of 17 July whereas $C_{\mathrm{s}}$ remained practically constant is somewhat unexpected. An appropriate explanation is that the upper layer of the bottom sediments (or the lowest water layer) mostly contains some algae species.

The concentration of suspended matter in the lowest layer of the water column considerably increased after the ship traffic started (Fig. 7). For example, on 20 July at 7:30, i.e. before the ship traffic begins, the average concentration of suspended matter was $4.1 \mathrm{~g} \mathrm{~m}^{-3}$. At 10:53, after nine fast ferries had passed, it was $4.9 \mathrm{~g} \mathrm{~m}^{-3}$. So the increase of $C_{\mathrm{s}}$ due to ship waves was about $0.8 \mathrm{~g} \mathrm{~m}^{-3}$ at a height of 0.7-1.2 m above sea bottom. On 17 July no drastic increase of $C_{\mathrm{s}}$ was observed.

The above-presented shows that the influence of the wakes lasts for a few minutes. Thus, this increase is evidently mostly caused by the last wake. Further, 


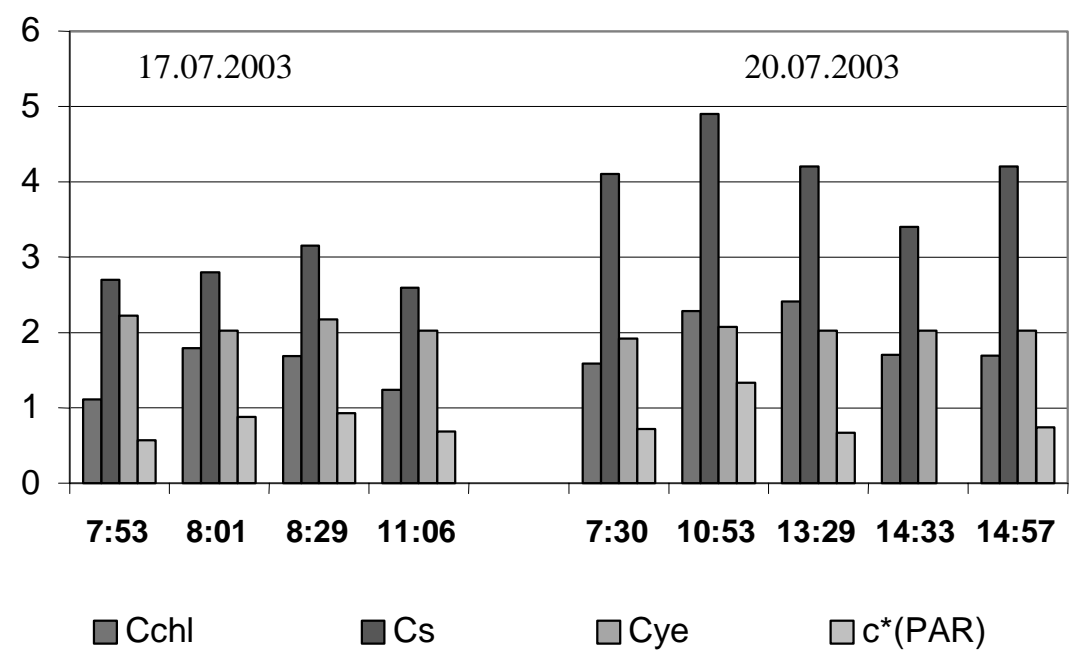

Fig. 7. The concentrations of chlorophyll $a\left(C_{\mathrm{chl}}, \mathrm{mg} / \mathrm{m}^{3}\right)$, suspended matter $\left(C_{\mathrm{s}}, \mathrm{g} / \mathrm{m}^{3}\right)$, and yellow substance $\left(C_{\text {ye }}, \mathrm{g} / \mathrm{m}^{3}\right)$ and the averaged (over $\left.400-700 \mathrm{~nm}\right)$ beam attenuation coefficient $\left(c^{*}(\mathrm{PAR}), \mathrm{m}^{-1}\right)$ of the near-bottom water samples taken on 17 and 20 July.

the data from the upper plane sensor suggest that the influence of wakes becomes evident only in the lowest layer with a thickness of about $1 \mathrm{~m}$. Therefore, a single wake of a fast ferry raises about $1 \mathrm{~g}$ of matter from each square metre of the strongly affected seabed area to the lower part of the water column with a depth of about $1 \mathrm{~m}$.

The rate of the increase of $C_{\mathrm{s}}$ is comparable with the typical measurement error of $C_{\mathrm{s}}$, formally suggesting that only qualitative conclusions can be based on this result. There are, however, some arguments in favour of the conclusion that the actual increase of $C_{\mathrm{s}}$ may be much larger. The main argument is the time shift between the maximum reaction of optical properties of water to a wake and the instant of sampling of water probes. The sampling procedure generally did not allow determination of the peak concentration of $C_{\mathrm{s}}$, which apparently occurred simultaneously with the large changes in optical properties of sea water and persisted for a short time. The water samples generally characterize only residual changes of water quality that persist during several minutes.

Owing to fast changes in the reaction of sea water to ship waves and the abovedescribed technical problems in water sampling, we failed to reliably connect changes in $K_{\mathrm{d}}(t)$ with the corresponding changes of the concentration of optically active substances (OAS) at the measurement sites. However, we had at our disposal results of simultaneous measurements of optical properties and concentration of OAS of sea water performed during monitoring underwater sand mining in a shallow coastal area of Muuga Bay next to Tallinn Bay in August-October 2003. 
A general description of these monitoring activities is given in Kask, 2003. The measurements were performed with the same equipment. The conditions for water sampling and optical measurements were favourable, because the optically dense water was mostly homogeneous.

Figure 8 shows that both the average $K_{\text {d,av }}(t)$ of $K_{\mathrm{d}}(t)$ over the surface layer with a thickness of $3 \mathrm{~m}$ and $c^{*}(\mathrm{PAR})$ depend practically linearly on $C_{\mathrm{s}}$ for a large range of the suspended matter concentrations, and the correlation between these quantities is particularly high. On the one hand, according to this dataset, an increase in $K_{\mathrm{d}, \mathrm{av}}(t)$ by $1 \mathrm{~m}^{-1}$ (which was actually observed at both the measurement sites, see Figs. 4 and 5) generally corresponds to an increase in $C_{\mathrm{s}}$ by about $20 \mathrm{mg} \mathrm{L}^{-1}$. On the other hand, an increase in $c^{*}(\mathrm{PAR})$ by $0.5-1 \mathrm{~m}^{-1}$ corresponds to an increase in $C_{\mathrm{s}}$ by about $1-2 \mathrm{mg} \mathrm{L}^{-1}$. The former conclusion apparently overestimates the amount of suspended matter but the latter one well matches the increase of $C_{\mathrm{s}}$ determined above from the water samples.

Comparison of all three estimates suggests that the actual increase in $C_{\mathrm{s}}$ owing to a typical single ship wake in the lowest water layer with a thickness of about $1 \mathrm{~m}$ for water depths of $2-5 \mathrm{~m}$ in the coastal area of Tallinn is about 1$2 \mathrm{mg} \mathrm{L}^{-1}$. The peak values of $C_{\mathrm{s}}$ in the lowest layer are probably much higher. Qualitatively, the increase in $C_{\mathrm{s}}$ apparently follows the behaviour of $K_{\mathrm{d}}(t)$. The plots in Fig. 5 suggest that the suspended matter remains in the water column (higher than about $0.5 \mathrm{~m}$ from the bottom) for about $5 \mathrm{~min}$.

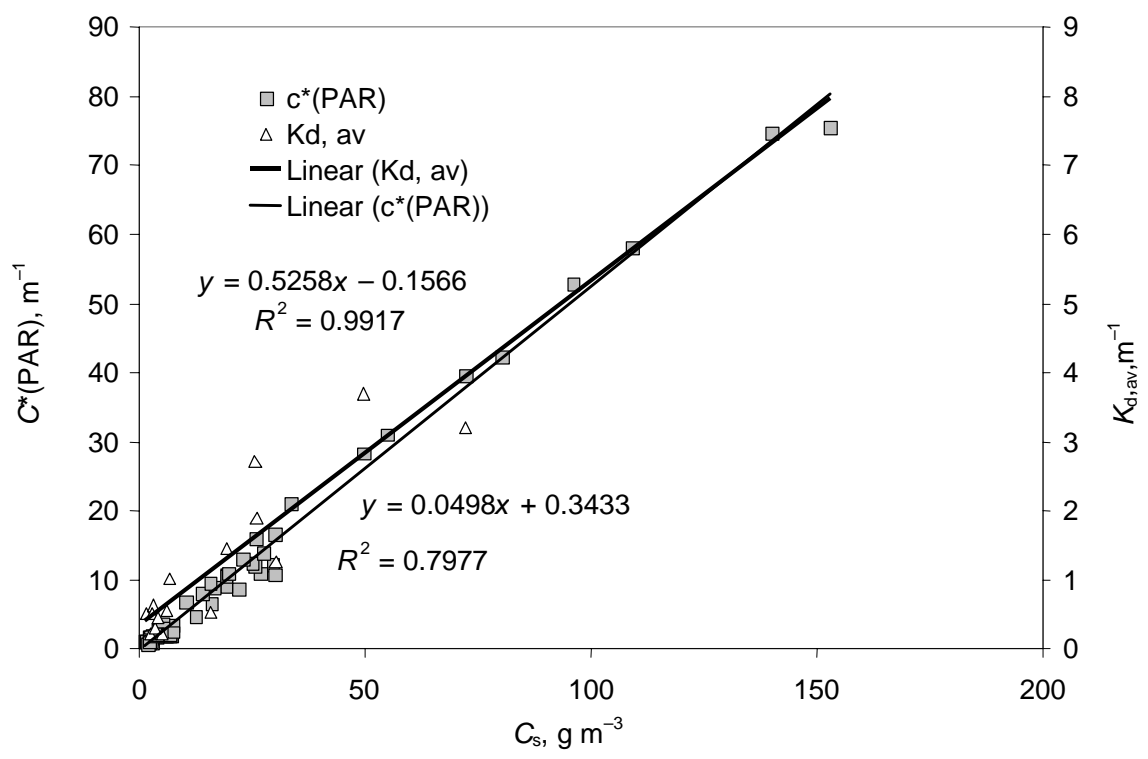

Fig. 8. Dependence of the averaged beam attenuation coefficient $c^{*}(\mathrm{PAR})$ and diffuse attenuation coefficient $K_{\mathrm{d}, \mathrm{av}}$ on the suspended matter concentration $\left(C_{\mathrm{s}}\right)$ in water samples during sand mining in Muuga Bay 22.09-17.10.2003. Diffuse attenuation coefficient $K_{\mathrm{d} \text {,av }}$ is averaged over the upper water layer at depths from 0 to $3 \mathrm{~m}$. 
The amount of sediments brought into motion by a single ship wake can be roughly estimated (Bauer et al., 2002) as the product of the amount of suspended matter in a unit of volume of the lowest water layer with increased concentration of suspended matter $\left(1 \mathrm{mg} \mathrm{L}^{-1}\right)$, the volume of water within this layer for a unit of area $\left(1000 \mathrm{~L} \mathrm{~m}^{-2}\right)$, and the width of the coastal zone with a depth of $2-5 \mathrm{~m}$ that is apparently affected by wakes $(250 \mathrm{~m})$. A single ship wake thus brings into motion about $250 \mathrm{~g}$ of sediments for each metre of the coastline of Tallinn Bay. If we take into account the high frequency of fast ferry traffic (28-34 ship crossings each day along the Tallinn-Helsinki ship lane) and the total duration of the navigation season (about 300 days each year) we will reach an interesting conclusion about the magnitude of the bulk sediment transport. Namely, annually fast ship traffic brings into motion about $2300 \mathrm{~kg}(1000 \mathrm{~L})$ of matter from each metre of the shoreline additionally to the sediment transport caused by natural factors.

The extent of the transport can be estimated as a product of the typical velocity of near-bottom currents in the area in question $\left(10 \mathrm{~cm} \mathrm{~s}^{-1}\right.$ according to Elken, 2002) and the typical time for which suspended matter remains in the water column (5 min). The actual bulk offshore sediment transport is much less indeed, because the actual wave loads, the structure of the bottom, and the velocity and direction of currents are highly variable (Soomere et al., 2002). The results obtained for boat-induced river bed erosion (Bauer et al., 2002) cannot be applied here directly. However, even if only $10 \%$ of it $(100 \mathrm{~L}$ of matter per each metre of shoreline) occurs offshore, the wave-induced sediment transport may correspond to an erosion of the shoreline by some dozens of centimetres annually, depending on the slope of the coast.

\section{CONCLUSIONS}

Many components of the local marine system of the Baltic Sea have historically been adjusted to low near-bottom velocities. For that reason, fast ship waves appear as a new forcing component at certain depths in the area. The presented data demonstrate that the large near-bottom velocities indeed become evident in resuspension processes (normally accompanied by sediment transport processes), which are detectable with the use of optical methods.

The reduced water transparency (equivalently, increased turbidity) generally has a suppressing effect on the bottom vegetation. The presented data, however, suggest that wake-induced increase of water turbidity does not necessarily result in drastic worsening of the underwater light conditions. A certain decrease in the amount of direct irradiance in some cases may be compensated for by a comparable increase in scattered light. However, this compensation apparently occurs for the cases when the affected water layer is relatively thin; otherwise the changes of the optical properties of sea water are certainly accompanied by a decrease in the amount of light in deeper layers. It should be noted that satellite tracking of sea areas adjacent to ship lanes generally does not identify any 
vulnerable areas or possible ecosystem damages, either because, as shown above, the vast majority of the effects are confined to a relatively thin layer close to the seabed that commonly is not visible through the surface layers.

The influence of ship traffic leads to an extensive response of water properties in the bottom layers, in particular, to an overall increase of the optical density of water at certain depths. This increase consists of two components. The long-term changes of the overall optical density can be detected with classical methods, including laboratory analysis of water samples taken at appropriate depths and sites. Local worsening of the water quality through extensive resuspension apparently is much larger but quite complicated to follow because of the short duration of the wake-induced resuspension events. Direct underwater optical measurements of the diffuse attenuation coefficient are particularly important in this context, because they may provide valuable information about the actual amount of material that is brought into motion and that cannot be detected by other means.

The amount of matter brought from the bottom into the water column is small for each single ship wake. However, the density of fast ferry traffic in Tallinn Bay is so high that its bulk influence, at least in certain coastal areas, may be highly significant. The above crude estimates show that the amount of sediments, jointly removed from the original location by ship wakes and local currents, may be of the order of $100 \mathrm{~L}$ of matter from each metre of the coast annually. For the real coastal profile this mass of fine sediments if transported seawards corresponds to the annual shoreline reduction by a few tens of centimetres.

\section{ACKNOWLEDGEMENTS}

The study was supported by the Estonian Science Foundation (grants Nos. 5595 and 5762) and by the Centre of Nonlinear Studies (CENS). Kalev Rannat constructed the pillar for wave measurements and operated with wave recorders. Andres Kask and Kalev Rannat were of great assistance in performing the optical measurements. Comments from two reviewers were very helpful in improving the final version of the paper.

\section{REFERENCES}

Arst, H. 2003. Optical Properties and Remote Sensing of Multicomponental Water Bodies. Springer Praxis Publishing, Chichester, U.K.

Arst, H., Erm, A., Kallaste, K., Mäekivi, S., Reinart, A., Nõges, P. \& Nõges, T. 1999. Investigation of Estonian and Finnish lakes by optical measurements in 1992-1997. Proc. Estonian Acad. Sci. Biol. Ecol., 48, 5-24.

Arst, H., Reinart, A., Erm, A. \& Hussainov, M. 2000. Influence of the depth-dependence of PAR diffuse attenuation coefficient on the computation of downward irradiance in different water bodies. Geophysica, 36, 129-139.

Bauer, B. O., Lorang, M. S. \& Sherman, D. J. 2002. Estimating boat-wake-induced levee erosion using sediment suspension measurements. J. Waterw. Port Coast. Ocean Eng., 128, 152-162. 
Bricaud, A., Roesler, C. \& Zaneveld, J. R. V. 1995. In situ methods for measuring the inherent optical properties of ocean waters. Limnol. Oceanogr., 40, 393-410.

Dera, J. 1992. Marine Physics. PWN, Warszawa and Elsevier, Amsterdam.

Elken, J. 2002. Hoovuste ja õlireostuse mudeli verifitseerimine hoovuseandmetega. In Muuga sadama merekeskkonnamõju seire 2002, hüdrodünaamika (Kõuts, T., ed.), pp. 99-110. Research Report, Marine Systems Institute at Tallinn Technical University, Tallinn.

Erm, A., Arst, H., Hussainov, M., Kutser, T. \& Reinart, A. 1999. Optical measurements in Lake Ülemiste. Proc. Estonian Acad. Sci. Biol. Ecol., 48, 63-75.

Erm, A., Arst, H., Trei, T., Reinart, A. \& Hussainov, M. 2001. Optical and biological properties of Lake Ülemiste, a water reservoir of the city of Tallinn I: Water transparency and optically active substances in the water. Lakes Reservoirs: Res. Manage., 6, 63-74.

Erm, A., Arst, H., Nõges, P., Nõges, T., Reinart, A. \& Sipelgas, L. 2002. Temporal variation of the bio-optical properties of four North Estonian lakes in 1999-2000. Geophysica, 38, 89-111.

Erm, A. \& Reinart, A. 2003. Optical properties of the system "Ice Cover + Water" in different type of water bodies. In Proc. IV Workshop on Baltic Sea Ice Climate, Norrköping, Sweden 2002, pp. 1-10, Oceanografi, 72, SMHI.

Guidelines for Managing Wake Wash from High-Speed Vessels. 2003. Report of Working Group 41 of the Marine Navigation Commission. International Navigation Association (PIANC), Brussels.

Herlevi, A., Virta, H., Arst, H. \& Erm, A. 1999. Results of light absorption/attenuation measurements in Finnish and Estonian lakes in summer 1997. Proc. Estonian Acad. Sci. Biol. Ecol., 48, 46-62.

Jerlov, N. G. 1968. Optical Oceanography. Elsevier, Amsterdam.

Kask, J. (ed.). 2003. Prangli ehitusliiva maardla ja selle laienduse kaevandamise eelne ja aegne keskkonna seire. Research report. Marine Systems Institute at Tallinn Technical University, Tallinn.

Kask, J., Talpas, A, Kask, A. \& Schwarzer, K. 2003. Geological setting of areas endangered by waves generated by fast ferries in Tallinn Bay. Proc. Estonian Acad. Sci. Eng., 9, 185-208.

Kirk McClure Morton. 1998. Investigation of High Speed Craft on Routes Near to Land or Enclosed Estuaries. Report JR226, The Maritime and Coastguard Agency, Southampton, UK.

Kofoed-Hansen, H. \& Mikkelsen, A. C. 1997. Wake wash from fast ferries in Denmark. In Fourth International Conference on Fast Sea Transportation FAST '97. Sydney, 1997, Vol. 1, pp. 471-478. Baird Publications, Hong Kong.

Leppäranta, M., Reinart, A., Erm, A., Arst, H. \& Sipelgas, L. 2003. Investigation of ice and water properties and under ice light field in fresh and brackish water bodies. Nord. Hydrol., 34, 245-266.

Lindholm, T., Svartström, M., Spoof, L. \& Meriluoto, J. 2001. Effects of ship traffic on archipelago waters off the Långnäs harbour in Åland, SW Finland. Hydrobiologia, 444, 217-225.

Lorenzen, C. J. 1967. Determination of chlorophyll and phaetopigments: spectrophotometric equations. Limnol. Oceanogr., 12, 343-346.

Mäekivi, S. \& Arst, H. 1996. Estimation of the concentration of yellow substance in natural waters by beam attenuation coefficient spectra. Proc. Estonian Acad. Sci. Biol. Ecol., 6, 108-123.

Paalme, T. 1997. Primary production of different species of algae measured in situ in Tallinn and Muuga bays (1992-1994). In Ecological Investigations in Tallinn Bay Area 1993-1997, pp. 19-31. Report series No. 8. Estonian Marine Institute, Tallinn.

Parnell, K. E. \& Kofoed-Hansen, H. 2001. Wakes from large high-speed ferries in confined coastal waters: Management approaches with examples from New Zealand and Denmark. Coastal Manage., 29, 217-237.

Reinart, A., Arst, H., Erm, A., Trei, T. \& Hussainov, M. 2001. Optical and biological properties of Lake Ülemiste, a water reservoir of the city of Tallinn II: Light climate in Lake Ülemiste. Lakes Reservoirs: Res. Manage., 6, 75-84. 
Reinart, A., Herlevi, A., Arst, H. \& Sipelgas, L. 2003. Preliminary optical classification of lakes and coastal waters in Estonia and south Finland. J. Sea Res., 49, 357-366.

Soomere, T. 2003. Tallinna lahe loodusliku lainetuse režiimist. Publ. Inst. Geogr. Univ. Tartu., 93, 227-241.

Soomere, T. \& Kask, J. 2003. A specific impact of waves of fast ferries on sediment transport processes of Tallinn Bay. Proc. Estonian Acad. Sci. Biol. Ecol., 52, 319-331.

Soomere, T. \& Rannat, K. 2003. An experimental study of wind and ship waves in the Tallinn Bay. Proc. Estonian Acad. Sci. Eng., 9, 157-184.

Soomere, T., Elken, J., Kask, J., Keevallik, S., Kõuts, T., Metsaveer, J. \& Peterson, P. 2002. Laevaliikluse purustav mõju Viimsi poolsaare, Aegna ja Naissaare randadele ning selle neutraliseerimise võimalused. Research report. Marine Systems Institute at Tallinn Technical University, Tallinn.

Soomere, T., Elken, J., Kask, J., Keevallik, S., Kõuts, T., Metsaveer, J. \& Peterson, P. 2003. Fast ferries as a new key forcing factor in Tallinn Bay. Proc. Estonian Acad. Sci. Eng., 9, 220242.

Varyani, K. S. \& Krishnankutty, P. 2002. Wave Wash of Stena Explorer in Dublin Bay. Wave Wash of NGV Liamone in Nice Port. Wave Wash of INCAT96 in Barcelona. EU Project TOHPIC, Documents Nos. 1.2.08.01, 1.2.08.02, and 1.2.08.03.

Zaneveld, J. R. V., Kitchen, J. C., Bricaud, A. \& Moore, C. 1992. Analysis of in situ spectral absorption meter data. In Ocean Optics XI, Proc. SPIE, 1750, 187-200 (in Russian).

\section{Kiirlaevalainete mõju Tallinna lahe vee optilistele omadustele}

\section{Ants Erm ja Tarmo Soomere}

On demonstreeritud, et kiirlaevade lained põhjustavad Tallinna lahe rannanõlval Aegna saare lähistel 2-5 m sügavuses alas vee optiliste omaduste märgatavaid muutusi $\mathrm{ca} 1 \mathrm{~m}$ paksuses põhjalähedases kihis. Ühe kiirlaeva möödumisel ülestõstetud kuivaine hulk on suurusjärgus $1 \mathrm{~g} / \mathrm{m}^{2}$ ning see püsib veesambas umbes 5 minutit. Kiirlaevaliikluse summaarne mõju võib põhjustada umbes 100 liitri setete ärauhtumise aastas iga rannajoone meetri kohta. 